\title{
CANAIS DE EXPORTAÇÃO DO CALCSADO BRASILEIRO
}

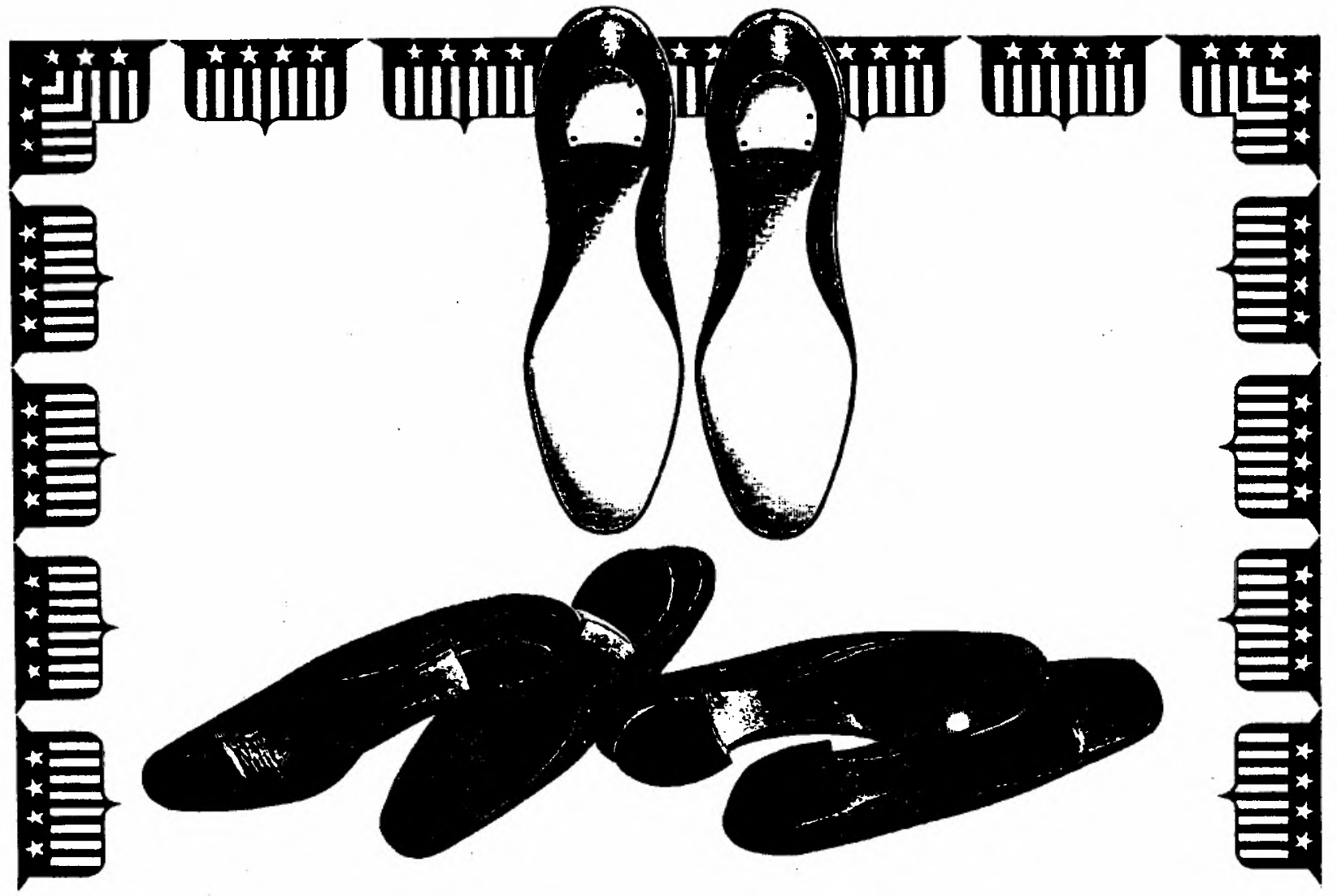

- MARCOS AURÉLIO MAZOCATO

Mestre em Administração pelo Programa de

Pós-Graduação em Administração da Universidade

Federal do Rio Grande do Sul e funcionário do Depto. de Promoção e mercados da CACEX.

RESUMO: Neste texto o autor descreve a estrutura de comercialização das exportações de calçados femininos, de couro, produzidos no Rio Grande do Sul e indica segmentos do produto que não estão sendo aproveitados pela indústria calçadista brasileira, tais como os produtos para desportos e os calçados de vinil e plástico.

PALAVRAS-CHAVE: Marketing, planejamento estratégico, canais de distribuiçãa, exportação, calçados, negociação, sinergia.
T ma pesquisa efetuada no segundo semestre de 1988, junto às 30 maiores empresas exportadoras de calçados femininos de couro, produzidos no Rio Grande do Sul, enfocando aspectos mercadológicos e de canais de distribuição, constatou o seguinte: Essas empresas exportaram durante o ano de 1987, acima de US\$ 4.500 .000 cada uma, e representaram, em conjunto, um volume efetivo de UŚ\$ 410.000 .000 .00 em calçados, correspondendo à $60 \%$ do total do produto brasileiro exportado. A maior delas comercializou com o exterior mais de US\$ $\$ 5.000 .000$, durante o ano focalizado.

\section{RETROSPECTIVA}

No início da década de 60 , apenas duas das empresas pesquisadas realizavam exportações. $\mathrm{O}$ total de calçados brasileiros exportados,então, era de pouco mais de 100.000 pares anuais, de todos 
os tipos, e o preço médio alcançava cerca de US\$ 1.00 por par.

Com o deslocamento da força de trabalho norte-americana para a produção de artigos de maior valor agregado, tais como máquinas e equipamentos, houve um desinteresse pela produção de calçados, o qual necessita intensivamente de mão-de-obra.

Os atacadistas norte-americanos procuraram, em outros países, fornecedores para atender às necessidades de consumo de seus clientes.

A Itália, principal fornecedor norte-americano, não tinha condições de suprir a intensa demanda ocasionada, ao passo que o Brasil iniciava seu modelo exportador, e ao mesmo tempo as indústrias brasileiras apresentavam capacidade ociosa, resultante de retração do consumo interno.

Surgiu, assim, uma oportunidade muito importante para a história das exportações brasileiras de manufaturados, que colocou o Brasil, ao lado da Taiwan, Itália e Coréia como um dos principais fornecedores mundiais de calçados que em 1988 aproximou-se dos 130.000 .000 de pares exportados, gerando divisas de US\$1.200.000.000, que representam quase $5 \%$ do total das exportações brasileiras $^{(1)}$.

O produto calçado, do ponto de vista mercadológico, apresenta características particulares em função de ser um artigo complementar do vestuário, rapidamente perecível, mutável e marcado por fatores subjetivos muito fortes pelo modismo, principalmente no segmento feminino.

Existem, basicamente, dois períodos de comercialização, bem diferenciados - o verão e $o$ inverno - , quando os produtos são caracterizados em função do benefício que devem proporcionar aos consumidores. E duas meias-estações, que não requerem necessariamente desenvolvimento de produtos específicos para os usuários.

No aspecto qualidade, existem limitadas alternativas que consistem na utilização de materiais sintéticos ou naturais. Muito embora haja preferência pelos insumos naturais, atualmente observa-se uma forte tendência de crescimento na participação dos produtos sintéticos, em decorrência da evolução desses materiais, que se tornam cada vez mais semelhantes aos naturais.

Isso ocorre não só em seus aspectos visuais, mas, também, pelas qualidades de maleabilidade, flexibilidade, densidade, maciez, impermeabilidade, enfim, por todo o conforto que o produto possa proporcionar ao consumidor.

O preço do produto exportado, nas séries históricas, apresenta uma evolução média da ordem de US\$1.00, em 1964, para US\$ 7.90, em
1987, tendo ultrapassado US $\$ 8.00$, em novembro de $1988^{(2)}$.

O preço praticado pelas empresas pesquisadas apresentou, em 1988, uma variação entre US\$ 4.00 e US $\$ 17.50$, e um preço médio mínimo de US\$ 7.18 e máximo de US\$12.03.

As empresas exportadoras encontravam-se, na ocasião da pesquisa, fundamentalmente voltadas para a produção. Concentravam seus esforços basicamente no aprimoramento da qualidade do produto e desenvolvimento dos recursos humanos de que dispunham, proporcionando aos intermediários a execução dos serviços aos clientes.

Por essas razões, na região produtora, atualmente existem mais de duas centenas de agentes de exportação que prestam serviços de desenvolvimento de produtos, acompanham o fluxo de produção diário dentro da própria empresa e, lá mesmo, realizam, em nome do comprador-intermediário, o controle de qualidade do produto encomendado.

A capacidade de produção dessas empresas varia de 3.000 a 27.000 pares, com uma média de 11.000 pares por dia.

O número de empregados, por empresa, está entre 500 e 6.500, com uma média, nas 30 empresas pesquisadas, de 2.188 empregados.

O volume mínimo desejado pelos exportadores para realizar uma negociação é, em média, 22.600 pares por pedido novo, sendo que os parâmetros mínimos exigidos ficam entre 1.500 e 50.000 pares, por pedido. (Pedido novo corresponde a uma encomenda inicial que representa para a empresa um investimento em vários insumos e materiais de produção específicos para atender àquela encomenda, tais como navalhas de cortes de couro e formas necessárias para a produção do lote negociado.)

Para proporcionar condições de produção a uma linha de calçados são necessários, no mínimo, 500 pares de formas a um custo de cerca de US\$ $12.00 \mathrm{o}$ par, as quais podem ser encomendadas às empresas especializadas e são produzidas em madeira ou sintéticos.

Os prazos de entrega dos pedidos, a partir da formalização da encomenda, variam de 45 a 90 dias. Em média, 68 dias.

Existem épocas de picos de demanda, durante o forte período de comercialização final do

1. BANCO DO BRASIL S.A., CARTEIRA DE COMERCIO EXTERIOR, DEPEC-Departamento de Estatística em Comércio Exterior, Rio de Janeiro.

2. ADICAL/U.S. Footwear Retailers Imports (dados disponíveis até novembro/88). 
produto, quando ocorrem "reordens" (repetições de pedidos) face ao sucesso de um determinado modelo junto aos consumidores finais.

Das empresas pesquisadas, uma única comercializa grande volume de produtos com sua própria marca $-60 \%$ de sua produção. Outras quatro empresas comercializam produtos com marca própria em percentuais que variam de $5 \%$ a $20 \%$ de suas capacidades de produção.

As demais, basicamente, produzem artigos com marcas de grandes atacadistas, representando, esse grupo, cerca de $85 \%$ da amostra. E $12 \%$ comercializam com marcas de terceiros, isto é, produtos adquiridos pelos atacadistas com marca de varejistas.

A forma de pagamento negociada nas exportações de calçados divide-se em, fundamentalmente, duas modalidades: cobrança e carta de crédito representando $41 \%$ e $59 \%$ das operações, respectivamente.

As agências de exportação, no caso do calçado brasileiro, constituem-se no principal elemento facilitador da negociação das exportações do produto, principalmente para o mercado norteamericano.

A maioria delas não adquirem título e posse do produto, unicamente realizando as tarefas de agenciadores dos negócios. Algumas operam de ambas as formas, adquirindo o produto para, em seu próprio nome, realizarem exportações, e também agenciando operações que serão efetivadas em nome do próprio fabricante.

Trading companies e empresas comerciaisexportadoras são os agentes intermediários que assumem a propriedade dos produtos para revendê-los no mercado externo. Essas empresas operam, principalmente, com os pequenos e médios fabricantes, aos quais, além de encomendas, também transferem apoio financeiro para aquisição de materiais e informações técnicas de produção.

Agentes, pois, sejam tradings, comerciaisexportadoras ou agentes importadores/exportadores, pelo conjunto de funções que exercem, pelo volume de mercadoria que agenciam ou comercializam e pelo poder que detêm, constituem-se no principal elemento de ligação do canal de exportação do calçado brasileiro.

\section{O MARKETING E A ESTRUTURA DA INDÚSTRIA}

A indústria brasileira de calçados é atualmente composta por mais de 4.000 empresas, cujo tamanho varia desde pequenos ateliers com produção artesanal, até grandes empresas extremamente verticalizadas que contam com unidades de aquisição de couros e de beneficiamento em curtumes próprios, fábricas de insumo - tais como colas e solados sintéticos e, no mercado interno, lojas de varejo que comercializam produtos seus e de terceiros. Essas empresas maiores têm mais de 6.000 empregados.

Essas empresas, apresentam concentrações regionais nos seguintes pólos: Vale do Rio dos Sinos, no Rio Grande do Sul; Franca, Birigui e Jaú, em São Paulo; Juiz de Fora e Belo Horizonte, em Minas Gerais; e São João Batista, em Santa Catarina.

O Rio Grande do Sul concentra as maiores, que respondem por mais de $60 \%$ das exportações de calçados brasileiros e se voltam especialmente para a produção de calçados femininos de couro ${ }^{(3)}$.

No mercado interno, algumas dessas empresas acham-se muito bem posicionadas dentro da filosofia de marketing, que preconiza o avanço da indústria produtora em direção do consumidor final, exercendo funções cada vez mais amplas no canal de distribuição, procurando situar-se cada vez mais próximo do cliente final, não só com a finalidade de reduzir custos mas, principalmente, procurando, o mais rapidamente possível, obter informações sobre o desempenho dos produtos e sobre os gostos e hábitos dos consumidores, para, antecipando-se à concorrência, oferecer os melhores produtos para satisfação dos clientes.

No mercado externo, toda a tarefa de pesquisa de mercado, identificação de tendências da moda, identificação de mudanças de hábitos está a cargo do grande atacadista ou grande agente de importação norte-americano que, muitas vezes, pode estar associado a redes de varejo, lojas de departamentos ou trading companies.

\section{O COMPOSTO MERCADOLÓGICO}

\section{a) Produto: um ponto de vista de exportação}

A criação e o desenvolvimento do produto "calçado" compreende uma série de atividades que vão desde a previsão de tendências da moda e do volume a ser comercializado até a compra de matéria-prima e a organização da mão-de-obra para a produção.

Todas essas atividades envolvem a utilização de várias entidades especializadas, entre as quais podemos destacar:

3. BANCO DO BRASIL S.A. Revista CACEX. Rio de Janeiro, no. 1066, p.5. 
ENTIDADES

AGÊNCIAS IMPORTADORAS

ATACADO E VAREJO

AGÊNCIAS EXPORTADORAS

FABRICANTES

\section{FEIRAS INTERNACIONAIS}

O produto calçado é classificado como um artigo de escolha para o consumo, altamente concorrido, altamente substituível, tanto em função de qualidade como de modelagem, que tem um ciclo de vida extremamente curto como todos os artigos de moda e é totalmente dependente de estação climática, quando o processo de identificação do que será consumido e a oferta mais abrangente possível de alternativas são fundamentais para os varejistas.

Para o fabricante, a constante alternância de modelagem representa um custo significativo, principalmente em duas áreas da indústria: a linha de produção, que a cada novo produto deve

\section{ATIVIDADES ESPECIALIZADAS}

- Pesquisam tendências da moda

- Identificam gostos

- Criam modelos

- Negociam pedidos com atacadistas e varejistas

- Oferecem serviços pós-vendas

- Acompanham o desempenho de mercado

- Passam informações aos agentes exportadores

- Determinam quantidades

- Fazem testes de mercado

- Sugerem preços às agências/fábricas

- Compram grandes quantidades

- Vendem pequenas quantidades

- Estocam/armazenam

- Determinam prazos e períodos de comercialização

- Ampliam o produto através de marcas

- Estabelecem pontos de vendas

- Recebem informações dos Agentes Importadores

- Negociam com o fabricante

- Acompanham quantitativamente a produção

- Acompanham qualitativamente a produção

- Dão assistência técnica ao fabricante

- Instalam capacidade de produção

- Compram matéria-prima

- Organizam e desenvolvem mão-de-obra

- Desenvolvem métodos de produção

- Confeccionam amostras

- Confeccionam os produtos

- Agrupam atacadistas, varejistas e agentes em locais privilegiados (hotéis), onde são realizadas negociações de grandes volumes de calçados.

passar por um processo de ajuste, e o setor de compras, que deverá abastecer os estoques da empresa com os materiais necessários à produção.

O desenvolvimento e a modelagem do calçado produzido pelas indústrias brasileiras para exportação, em $91 \%$ dos casos, são realizados pelo importador ou pela agência de exportação; apenas 9\% das indústrias desenvolvem produtos próprios.

As especificações do produto, previamente negociado entre agentes e importadores, são alteradas em $87 \%$ das negociações entre os primeiros e os fabricantes, com o objetivo de ajustar o produto aos preços praticados pela indústria. 
Somente $13 \%$ das negociações entre agentes e fabricantes ocorrem sem modificações em itens do modelo original. Basicamente, esse processo visa a alterar insumos e materiais como partes internas (forro e palmilha), com o objetivo de ajustar o preço do produto.

A qualidade pode ser entendida tanto do ponto de vista dos insumos utilizados na fabricação do produto, como da mão-de-obra mais ou menos qualificada empregada na sua confecção. Existem modelos que podem ser produzidos pela montagem de poucas peças distintas, como cabedal, solado, salto e forro, incorporando pouca mão-de-obra. Outros recebem tratamento em ateliers com alta incidência de mão-de-obra, como costuras especiais e trançados. Dessa forma, a qualidade é função tanto dos insumos como couro e colas, como da habilidade dos artesãos que fazem as costuras e outros trabalhos artesanais, como os trançados.

Os termos internacionais de comércio utilizados pela indústria calçadista exportadora do Brasil são, em $90 \%$ dos casos, FOB (livre a bordo) e, fundamentalmente, para os embarques destinados ao mercado norte-americano.

Em 10\% das situações são negociados termos $\mathrm{C} \& \mathrm{~F}$ (custo e frete), e ocorrem nas exportações à Europa. As operações estabelecidas em termos CIF (custo, seguro e frete) perfazem $0,15 \%$ do total negociado e, também, ocorrem em operações com países europeus.

As formas de embarque utilizadas pelos exportadores são, em $83 \%$ dos casos, por via marítima. A incidência de $17 \%$ das exportações por via aérea implica duas situações distintas: quando ocorrem atrasos de produção e as despesas adicionais de frete são assumidas pelos fabricantes, situação em que há uma grande redução do lucro da operação, ou quando o importador reordenou um pedido inicial, em meio a época de comercialização, e necessitando com urgência da mercadoria em seus estoques, assume os custos do transporte aéreo.

\section{b) Preço}

O preço do calçado é inicialmente estabelecido pelo atacadista ou varejista norte-americano ao escolher os modelos que lhe são apresentados em feiras de amostra. A partir dessa informação inicial, são realizadas negociações entre agentes e fabricantes, que deverão encontrar um preço de consenso.

A negociação ocorre em função de volumes, especificações, incidência de mão-de-obra e oportunidade. $\mathrm{O}$ mercado produtor brasileiro é composto por um grande número de empresas dos mais diversos portes, e o processo de decisão do preço dá-se em um mercado de concorrência perfeita.

Há épocas de muita demanda por produtos, que determinam um acréscimo nos preços praticados pelos fabricantes e, da mesma forma, ocasiões de baixa procura, quando fabricantes produzem abaixo de seu nível de lucro, simplesmente com o objetivo de manter suas unidades fabris em funcionamento.

Em regra, a tradição que é mantida pela maioria das empresas proporciona um nível satisfatório de negócios perenes entre fabricantes e agentes exportadores.

\section{c) Promoção}

Toda a atividade promocional do calçado é realizada pelos intermediários de ponta do canal de distribuição, ou seja, os atacadistas e varejistas. Os fabricantes não participam dessas atividades, principalmente considerando-se que os produtos exportados raramente são comercializados no varejo com marca do fabricante.

Observa-se que no início do canal o produto tem um preço que embute apenas custos e lucro do fabricante, e comissão do agente de exportação ao nível de US\$7.00, enquanto que no varejo é oferecido por US\$27.00(4).

O ciclo de vida do produto também permite explicar esse afastamento do fabricante em relação aos aspectos mercadológicos promocionais do produto, pois, sendo um artigo altamente perecível (três meses de comercialização no varejo), com a proximidade da mudança de estação climática, os varejistas devem rapidamente vender seus estoques para poderem armazenar os novos artigos que deverão oferecer no período de comercialização seguinte.

\section{d) Distribuição Física}

$\mathrm{Na}$ distribuição física do produto, o fabricante deve preocupar-se em cumprir rigidamente os prazos estabelecidos na carta de crédito, entregando o produto aos prepostos dos importadores, que providenciam a contratação de navios para o transporte e o seguro das mercadorias. Se o prazo não for cumprido, deverá o fabricante, às suas expensas, providenciar o frete aéreo da mercadoria, para não perder o negócio totalmente mas, evidentemente, seu lucro ficará bastante reduzido.

Isso pode ser explicado, novamente, pelo ciclo de vida do produto: por maior que seja o sucesso

4. REVISTA Exame, 26.12.88, p.87. 
de um modelo junto ao público consumidor, sua fase de comercialização não durará mais de três meses; assim, é necessário proceder com urgência na entrega da mercadoria.

\section{O CONCEITO DE MARKETING NA EXPORTAÇÃO DE CALÇADOS}

$O$ conceito de marketing, aceito pelos principais autores, tem por definição o atendimento, da melhor forma possível, dos desejos dos consumidores e ensina as empresas a produzirem para suprir as necessidades dos mercados. Estrategicamente, pode-se entender que as empresas devam procurar caminhos de acesso a seus consumidores de forma eficiente, eficaz e efetiva como, por exemplo, com o aprimoramento dos serviços acoplados aos produtos, os melhores serviços pós-vendas, a criação de canais de comunicação que, no menor prazo possível, forneçam feedback aos fabricantes sobre o desempenho dos produtos.

Essas informações permitem, por meio de ajustes e desenvolvimento, a mais ampla forma de satisfação do consumidor na utilização do produto.

Por uma questão logística, as informações chegam aos fabricantes de maneira mais rápida e pura quanto mais próximo o fabricante estiver do cliente; e mais demorada, filtrada ou manipulada, quanto maior for a distância entre eles. Em outras palavras, quanto menos intermediários houver em um canal de distribuição, mais rápida e eficiente será a comunicação entre consumidor e fabricante, e mais rapidamente o produto poderá ser aperfeiçoado.

No caso do calçado produzido no Brasil para exportação, vemos a grande maioria das empresas voltadas unicamente para a produção. Preocupadas tão somente com o desenvolvimento de como fazer, aos menores custos possíveis, deixam para os intermediários todas as decisões mais próximas do cliente final, ou seja, o que fazer, quando fazer, para quem fazer, quanto fazer e a que preço fazer.

Dessa forma, todas as potencialidades dos mercados e dos produtos são exploradas por intermediários que, não só desempenham todas as funções seguintes à de produção, como também indicam aos fabricantes os modelos a serem produzidos, estabelecem prazos de entrega e padrões de qualidade dos produtos. Além disso, acompanham de forma efetiva e diária a evolução do processo de fabricação, realizando o controle de qualidade.

O intermediário é um elemento importantíssimo para o processo de comercialização de qual- quer produto, pelas vantagens que proporciona ao reduzir o esforço dos consumidores para localizar o produto desejado.

Uma grande loja de departamentos, um shopping, contêm num mesmo local várias alternativas de escolha de um produto para um consumidor.

Dessa forma, alguns fatores que determinam a preferência de um consumidor por determinado produto são perfeitamente identificáveis por um observador mais atento: a comodidade, a fácil localização, a própria presença do produto em locais visíveis que geram impulsos de compra.

Entretanto, outros fatores como a atualidade do produto, sua facilidade em complementar um conjunto de vestuário (para o caso do calçado) são tarefas que só podem ser elaboradas por especialistas que constantemente se atualizam no desenvolvimento dos fatores determinantes isto é, inovações da tecnologia e da moda, comportamento dos segmentos de renda de cada mercado - e, pelo desenvolvimento de um feeling que permita antecipar com alguma precisão o que será consumido nos próximos seis meses ou um ano.

Essas atividades, entre outras, permitem o conhecimento do comportamento do consumidor, a identificação dos diversos segmentos de consumidores e a constante atualização do produto.

Um exemplo da preocupação que os produtores devem ter no posicionamento de suas funções, estrategicamente cada vez mais próximas do consumidor final, pode ser encontrado na descrição de $O$ Estrategista em $A c ̧ a \tilde{a} 0^{(5)}$, que relata a estratégia de comercialização de empresas japonesas no comércio exterior:

"A sabedoria dessas corporações está na forma seqüencial como empregam seus recursos de marketing". Após a comercialização inicial através de trading como marca de terceiros, uma vez convencidas da qualidade e baixo custo de fabricação dos seus produtos, elas vão superando as deficiências do seu marketing e gradualmente dispensando o trabalho das 'trading companies', em primeiro lugar, depois das distribuidoras e, por fim, das fornecedoras de marcas".

\section{MERCADOS MUNDIAIS E CONCORRÊNCIA}

O principal mercado mundial consumidor de calçados é formado pelos Estados Unidos, que importam de outros países mais de $90 \%$ de seu consumo total. Compreende uma população

5. OHMAE, Kenchi. O Estrategista em Ação. São Paulo, Pioneira, 1982. 
grande, culturalmente homogênea, detentora de uma das maiores rendas per capita do planeta, com alta propensão ao consumo. É um mercado altamente competitivo, que desenvolveu mecanismos muito fortes de preservação de seus fundamentos capitalistas, e onde qualquer cidadão ou empresa que se sentir lesado(a) por práticas desleais de comércio pode registrar queixa em organismos ligados ao governo, que será investigada em no máximo 45 dias; e, sendo confirmada, implicará em severas represálias contra os culpados. Essas medidas, entretanto, muitas vezes podem incorporar um comportamento altamente protecionista da economia norte-americana, em detrimento da saudável prática do livre comércio mundial e dos mecanismos de concorrência perfeita.

De qualquer maneira os EUA são a maior e melhor alternativa de exportação de calçados para os outros países.Seu consumo em, $1988^{(6)}$ superou 1.100 bilhões de pares, de todos os tipos, os quais foram adquiridos a um preço médio de US\$ 10.66 para artigos de couro, US\$ 4.00 para os de vinil e plástico e menos de US $\$ 4.00$ para os demais. Em termos per capita, o consumo de calçados nos EUA tem apresentado uma média anual de cinco pares ${ }^{(7)}$.

O Brasil participa desse mercado, principalmente como exportador de calçados de couro femininos, vendidos a um preço médio de US\$ 8.45 por par. Na tabela 1 , verifica-se que as exportações brasileiras de calçados para os EUA concentram-se em três segmentos de preço, que vão de US\$2.51 até US\$12.00. Vê-se aí também que esses três segmentos tomados em conjunto equivalem a uma venda de 88.978 .000 pares/ano, dos quais 80.790 .000 são calçados femininos de couro. Esses números representam $85 \%$ do total das exportações de calçados, de todos os tipos, e mais de $90 \%$ das de calçados femininos de couro efetuadas pelo Brasil.

A tabela 2 apresenta os principais fornecedores de calçados, de todos os tipos, para o mercado norte-americano. Especialistas do setor apontam, segundo informações colhidas durante a pesquisa, a China e o México como os países que têm apresentado mais rápida evolução, tanto em quantidade de produtos exportados, como nos aspectos de preço e qualidade.

A Europa constitui o segundo mercado mundial consumidor de calçados brasileiros, com uma participação crescente, que evoluiu de 7\% das exportações brasileiras de calçados em 1986, para $18 \%$ em $1988^{(8)}$.

O governo norte-americano tem ocasionado, nos últimos anos, dificuldades de ordem política para as exportações brasileiras de calçados, em
TABELA 1

Segmentos de preço das exportações de calçados brasileiros para os EUA

\begin{tabular}{lrr}
\multicolumn{3}{l}{ 1-Todos os tipos } \\
\hline Preço & - & Pares/ano \\
\hline Até & US\$1.25- & 786.000 \\
US $\$ 1.26 \mathrm{a}$ & $\$ 2.50-$ & 788.000 \\
$\$ 2.51 \mathrm{a}$ & $\$ 5.00-$ & 18.891 .000 \\
$\$ 5.01 \mathrm{a}$ & $\$ 8.00-$ & 33.615 .000 \\
$\$ 8.01 \mathrm{a}$ & $\$ 12.00-$ & 36.472 .000 \\
$\$ 12.01 \mathrm{a}$ & $\$ 16.00-$ & 8.793 .000 \\
$\$ 16.01 \mathrm{a}$ & $\$ 20.00-$ & 2.814 .000 \\
$\$ 20.01 \mathrm{a}$ & $\$ 25.00-$ & 1.115 .000 \\
Acima de & $\$ 25.00-$ & 532.000 \\
\hline Total & & 103.806 .000 \\
\hline
\end{tabular}

\section{2 - Somente calçados femininos de couro}

\begin{tabular}{|c|c|c|}
\hline Preço & - & Pares/ano \\
\hline$\overline{\text { Até }}$ & US\$1.25- & 629.000 \\
\hline US $\$ 1.26 \mathrm{a}$ & $\$ 2.50-$ & 464.000 \\
\hline$\$ 2.51 \mathrm{a}$ & $\$ 5.00-$ & 15.940 .000 \\
\hline$\$ 5.01 \mathrm{a}$ & $\$ 8.00-$ & 30.871 .000 \\
\hline$\$ 8.01 \mathrm{a}$ & $\$ 12.00-$ & 33.979 .000 \\
\hline$\$ 12.01 \mathrm{a}$ & $\$ 16.00-$ & 6.151 .000 \\
\hline$\$ 16.01 \mathrm{a}$ & $\$ 20.00-$ & 1.032 .000 \\
\hline$\$ 20.01 \mathrm{a}$ & $\$ 25.00-$ & 667.000 \\
\hline Acima de & $\$ 25.00-$ & 323.000 \\
\hline Total & - & 89.055 .000 \\
\hline
\end{tabular}

Fonte: Adical/U.S. Footwear Retailers Imports, dados disponíveis até nov.88.

conseqüência das constantes ameaças de retaliações aos produtos brasileiros em geral. Esse tem sido o principal fator de redirecionamento das exportações brasileiras para a Europa.

Os demais países do mundo têm pequena participação no comércio mundial de calçados, como

6. ADICAL - ASSOCIAÇÃO DAS INDÚSTRIAS DE CALÇADOS DO RIO GRANDE DO SUL, in U.S. Footwear Retailers Imports, Novo Hamburgo-RS.

7. BANCO DO BRASIL S.A. Revista CACEX. Rio de Janeiro, no. 23, 29.02.1988.

8. BANCO DO BRASIL S.A./CACEX/DEPEC ADICAL. 
TABELA 2

\section{Principais fornecedores norte-americanos - 1988}

\begin{tabular}{|c|c|c|c|}
\hline & $\begin{array}{c}\text { Volume } \\
\text { Pares(1.000) }\end{array}$ & $\begin{array}{c}\text { Preço/U. } \\
\text { US\$ }\end{array}$ & $\begin{array}{c}\text { Valor } \\
\text { US } \$(1.000)\end{array}$ \\
\hline Taiwan .................... & 363.419 & 6.37 & 2.137.871 \\
\hline Coréia...................... & 219.292 & 9.71 & 2.129 .980 \\
\hline China ...................... & 144.515 & 3.96 & 292.164 \\
\hline Brasil ....................... & 104.089 & 8.45 & 879.271 \\
\hline Itália.......................... & 40.485 & 18.72 & 757.942 \\
\hline México ..................... & 32.294 & 3.14 & 101.312 \\
\hline Hong Kong ......... & $\quad 28.638$ & 4.69 & 134.171 \\
\hline Espanha ................ & $\quad 21.722$ & 15.10 & 328.021 \\
\hline
\end{tabular}

Fonte: Adical/U.S. Footwear Retailers Imports, dados disponíveis até nov.88.

consumidores de produtos importados. Canadá e Austrália são os mais significativos, com participações inferiores a $3 \%$ das exportações brasileiras.

\section{SUGESTÕES AOS FABRICANTES}

A indústria brasileira exportadora de calçados registra 25 anos de experiência. Apresentou, como ponto forte, um reduzido custo de mão-de-obra em relação aos concorrentes do resto do mundo. Aproveitou muito bem essa vantagem competitiva e sua capacidade de produção ociosa para ingressar em mercados externos.

Na produção, novos processos tiveram que ser implantados, ajustando suas linhas à pro dução em larga escala e obtendo ganhos de custo, em função de equipamentos mais modernos e o aproveitamento das vantagens proporcionadas pelas curvas de experiência. Na comercialização, pouco a pouco, foram se ajustando ao sistema desejado pelos compradores, especialmente quanto ao cumprimento de prazos de entrega e ao padrão de qualidade desejado pelo mercado.

Pode-se observar um grande distanciamento entre a moderna prática mercadológica e o procedimento praticado pela indústria calçadista exportadora. $\mathrm{O}$ aspecto comercial das operações de exportação de calçados brasileiros indica que o setor industrial mantém-se preso a um sistema tradicional de comportamento mercadológico, que remonta às décadas de 1940 e 1950.

Além da disponibilidade de mercados ávidos por consumo e da capacidade dos empresários nacionais, não devemos nos esquecer de registrar a grande colaboração que o governo proporcionou a todo o setor produtivo/exportador do Brasil, com a implantação de um modelo econômico exportador, oferecendo uma série de incentivos, que permitiram a empresas pouco competitivas no mercado externo disputar mercado com os demais concorrentes de outros países.

A indústria nacional de calçados, desconhecendo o mercado consumidor em sua essência, necessitou da ajuda dos importadores estrangeiros que desempenhavam todas as funções mercadológicas necessárias à comercialização do produto. Essa situação até hoje perdura.

O domínio do canal de exportação tem repousado totalmente nas mãos dos agentes exportadores/importadores e atacadistas/ importadores, que desempenham os papéis estratégicos de desenvolvimento do produto e acompanhamento da evolução das tendências da moda, conhecem os gostos e preferências dos consumidores e aprimoram os canais de comercialização, desenvolvendo marcas próprias, pontos exclusivos de vendas, relacionamento estreito e tradicional com os varejistas, vendas por catálogos, participação em feiras e todo o mix de serviços pós-vendas necessário a um bom desenvolvimento de negócios.

Aparentemente, torna-se necessária a comercialização com uma quantidade de diferentes modelos, muito maior que a capacidade das maiores empresas de diversificar suas linhas, para bem atender aos intermediários atacadistas e varejistas.

Apesar da relativa atração que o sistema de comercialização em vigor apresenta para os fabricantes, os quais recebem na própria empresa os modelos para produzir, nesse mesmo local, eles obtém a aprovação do comprador, através de seus agentes, para o embarque dos produtos confeccionados.

O afastamento do consumidor por um longo período proporciona aos fabricantes uma dependência estrategicamente perigosa, gerando uma miopia mercadológica que, eventualmente, poderá determinar sérios prejuízos à sobrevivência das empresas, dentro da dinâmica do mundo moderno.

O início de um posicionamento mercadológico mais eficiente e efetivo começa pela visão que o empresário deve ter de seu produto, reconhecendo que o produto manufaturado em sua unidade fabril não é, tão somente, o calçado na própria acepção da palavra, mas tudo o que decorre do produto em si: desde o transporte até o acompanhamento junto aos consumidores, $o$ 
desempenho que a mercadoria apresenta, o grau de satisfação que proporciona ao usuário final.

Nesse sentido, o valor da sinergia proporcionada pelo fluxo do produto apresenta nichos de lucro que devem ser melhor explorados pelos fabricantes brasileiros, tais como: o transporte internacional e o seguro até o porto de desembarque, itens que tradicionalmente são decididos por prepostos do importador e considerados como atividades sem atratividade para a indústria.

Esses itens, que representam entre $6 \%$ e $10 \%$ da operação de exportação, quando bem administrados, podem, não só representar uma vantagem competitiva, pela apresentação de um melhor serviço aos clientes, como também gerar lucros suplementares ao empresário que souber obter ganhos na negociação com as empresas de transporte e as seguradoras, considerando o volume e a frequiência das operações.

\section{SUGESTÕES AO GOVERNO}

A participação governamental, através de seus órgãos de administração direta e indireta, foi fundamental para o desenvolvimento do programa exportador brasileiro.

O setor manufatureiro calçadista é um exemplo de sucesso do programa exportador brasileiro, detendo quase $60 \%$ do mercado norte-americano de artigos femininos de couro, no segmento de preços entre US $\$ 5.00$ e US\$12.00, e $31 \%$ do volume total do produto importado no mesmo mercado. Entretanto, deve-se procurar analisar que essa excessiva especialização não é favorável sob uma ótica estratégica de permanência no mercado por longo prazo.

Ao analisarmos os fatores que levaram o produto brasileiro a ter uma participação tão significativa no maior mercado mundial, devemos observar que outros segmentos integrantes do mercado consumidor calçadista também podem ser alcançados. A tabela 3 fornece dados sobre eles nos EUA.

O segmento feminino de calçado de couro pode alavancar o ingresso em outros segmentos de mercado onde o produto, o processo de comercialização e os processos de produção são muito semelhantes. Experts avaliam, segundo informações obtidas durante a pesquisa, a tendência de crescimento dos segmentos atléticos em detrimento dos demais, face ao grande desenvolvimento tecnológico de solados derivados de petróleo que se aproximam da qualidade do produto natural (couro) e ao mesmo tempo agregam outros itens de qualidade não encontrados no produto natural.
TABELA 3 Consumo norte-americano de calçados

\begin{tabular}{lc}
\hline Tipo de consumidor & Pares \\
\hline Masculino: & -80.000 .000 \\
-couro & -60.000 .000 \\
-vinil e plástico & -40.000 .000 \\
-outros & \\
\hline Feminino: & -250.000 .000 \\
-couro & -220.000 .000 \\
-vinil e plástico & -80.000 .000 \\
-outros & -30.000 .000 \\
\hline Crianças: & -80.000 .000 \\
-couro & -25.000 .000 \\
-vinil e plástico & \\
-outros & -200.000 .000 \\
\hline Atléticos: & -60.000 .000 \\
-couro & \\
-vinil e plástico &
\end{tabular}

Fonte: Adical/U.S. Footwear Retailers Imports, dados disponíveis até nov.88.

A pesquisa revela que $95 \%$ dos empresários realizam vendas "FOB" (livre a bordo), em função de tradição.

Alguns poucos imaginam que teriam dificuldade em organizar um setor especificamente para atender aos embarques de mercadorias, e consideram essa atividade um ônus adicional para a empresa e não, como de fato se constitui, uma oportunidade de agregar valor ao processo comercial de exportação.

Um grande número de empresários acredita que, não considerando o custo acima mencionado, não teriam dificuldades em negociar seus produtos nos termos "CIF" (custo, seguro e frete) ou "C\&F" (custo e frete).

Para o país, esse novo procedimento representaria um ganho no fluxo de caixa das exportações de até $10 \%-2 \%$ correspondendo ao seguro e $8 \%$ ao frete (segundo informações de empresas de transporte e seguro) - além de assegurar um dominio dos fabricantes sobre importantes variáveis da distribuição.

A análise dos segmentos mais representativos para o calçado brasileiro no mercado norteamericano revela que o Brasil tem uma participação de cerca de $50 \%$ em três importantes segmentos do produto calçado de couro feminino, nas faixas de US\$ 2,5l a 5,00, US\$ 5,0l a 8,00 e 8,01 a 12,00 , conforme se vê na tabela 4 . 
TABELA 4

Consumo Norte-Americano e Importações de Calçados Femininos de Couro, Brasil, 1988:

\begin{tabular}{llccc}
\hline $\begin{array}{l}\text { Preço } \\
\text { Dólares }\end{array}$ & $\begin{array}{c}\text { Consumo } \\
\text { Total }\end{array}$ & $\begin{array}{c}\text { Exportações } \\
\text { Brasileiras }\end{array}$ & (1.000 pares) \\
\hline$\$ 1,26$ a & $\$ 2,50$ & 3.210 & 464 & Participação \\
$\$ 2,51$ a & $\$ 5,00$ & 33.750 & 15.940 & $14.4 \%$ \\
$\$ 5,01$ a & $\$ 8,00$ & 56.682 & 30.871 & $47.2 \%$ \\
$\$ 8,01$ a & $\$ 12,00$ & 60.835 & 33.979 & $54.4 \%$ \\
$\$ 12,01$ a & $\$ 16,00$ & 23.437 & 6.151 & $55.8 \%$ \\
$\$ 16,01$ a & $\$ 20,00$ & 10.963 & 1.032 & $26.2 \%$ \\
\hline
\end{tabular}

Fonte: Adical/U.S.Footwear Retailers Imports, dados disponíveis até nov. 88.

TABELA 5

Segmentos de Produto Não Explorados pelo Brasil

Produto

Estimativa de Consumo/Ano

(pares/1.000)

Calçados Masculinos de Vinil ou PLástico

35.610

Calçados Femininos de Vinil ou Plástico

191.000

Calçado Infantil em geral

63.000

Calçado Atlético em geral

254.000

Outros tipos de calçados

79.830

Fonte: Adical/U.S.Footwear Retailers Imports, dados disponíveis até nov. 88.

Existem importantes segmentos de produto nos EUA não explorados pelo Brasil, conforme se vê na tabela 5 .

Constata-se, portanto, a total ausência de um posicionamento mercadológico competitivo por parte dos produtores brasileiros de calçados no mercado mundial, pela não participação de marcas brasileiras e nenhum domínio sobre os diversos estágios dos canais de distribuição.

No mercado norte-americano, além da crescente participação dos fabricantes chineses e mexicanos, pode-se observar a existência de importantes segmentos de produtos e preços que não vêm sendo explorados pelas indústrias brasileiras, as quais têm direcionado suas exportações de calçados principalmente para três faixas de preços. Tais segmentos representam oportunidades para a diversificação ou para o ingresso de novas empresas no mercado exportador. ${ }^{(9)}$

9. Este trabalho é uma versão revista de parte da dissertação de Mestrado em Administração de Empresas, Canais de distribuição na exportação - descrição da estrutura de distribuição das exportaçôes de calçados femininos produzidos no Vale do Rio dos Sinos, no Rio Grande do Sul, defendida pelo autor na Universidade Federal do Rio Grande do Sul em abril de 1989 e disponível para consulta na Biblioteca da Faculdade de Ciências Econômicas dessa universidade.

ABSTRACT: In this paper the author describes the trade structure of female leather footwear exports manufactured in Rio Grande do Sul.

The last part is dedicated to indicate several segments not utilized by brazilian industries such as sport footwear, vinil and plastic shoes.

KEY TERMS: Marketing, middle-man agent in export, marketing exporting channels, negotiation, dominion, footwear, marketing strategy. 


\section{APÊNDICE}

\section{Canais de Distribuição na Exportação}

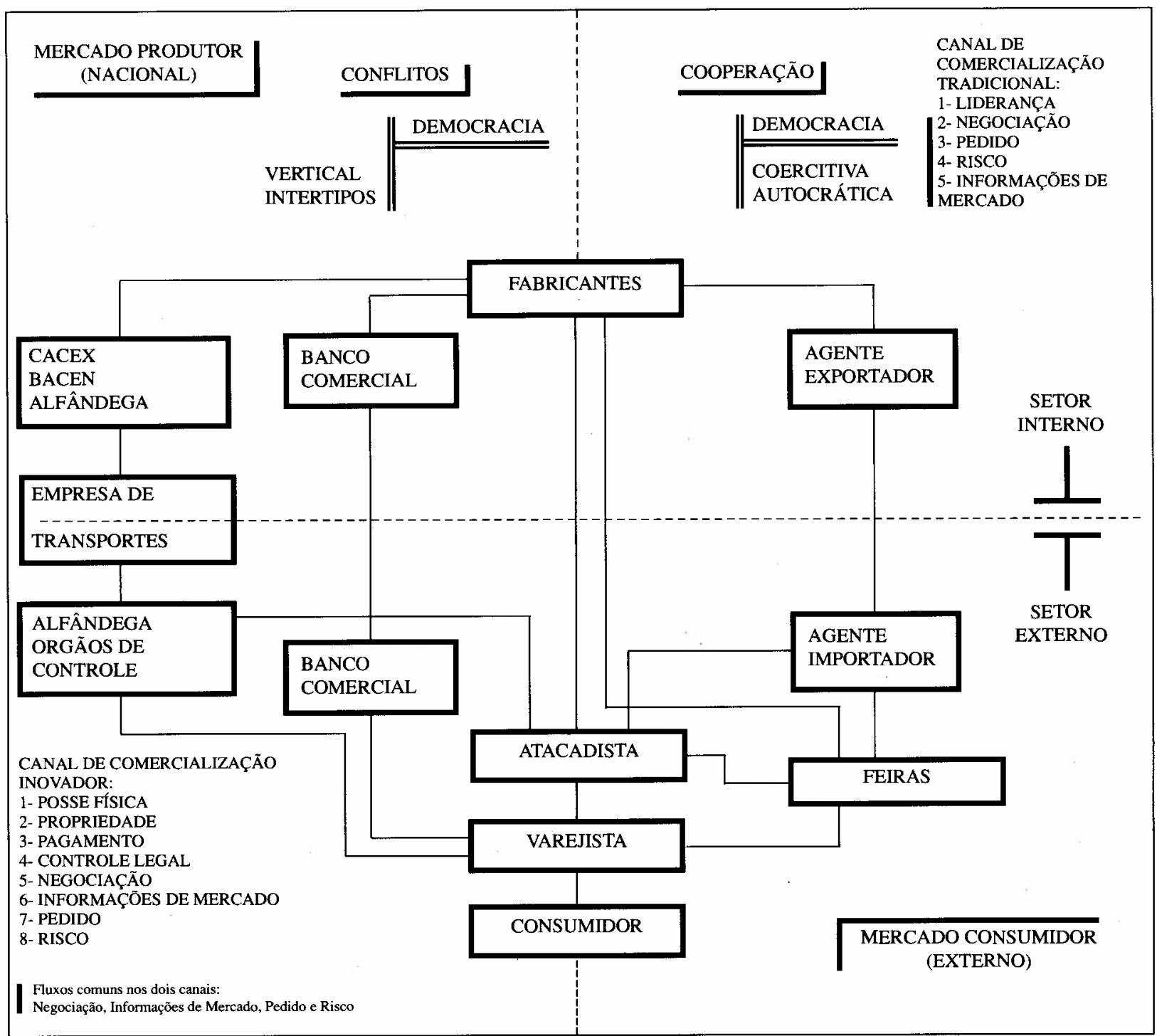

\section{BIBLIOGRAFIA COMPLEMENTAR}

BANCO DO BRASIL S.A., CARTEIRA DE COMÉRCIO EXTERIO, R. Manual do Exportador. RJ, 1988.

BUCKLIN, Louis P. A Theory of Distribution Channels Structure. Berkeley, Institute of Business and Economics Research, 1966.
LEVITT, Theodore. A Imaginação em Marketing. São Paulo, Atlas, 1985.

KOTLER, Philip. Marketing Management. Englewood Cliffs, N.J., Prentice Hall, 1988.

PORTER, MichaelE. Estratégia Competitiva. Rio de Janeiro, Campus, 1988.

TOFFLER, Alvin. A Empresa Flexível. Rio de Janeiro, Record, 1985.

ZAJDSZNJDER, Luciano. Teoria e Prática da Negociação. Rio de Janeiro, José Olympio, 1985.] 